\title{
Distributions of putative aerobic methanotrophs in diverse pelagic marine environments
}

\author{
Patricia L Tavormina ${ }^{1}$, William Ussler III $^{2}$, Samantha B Joye ${ }^{3}$, Benjamin K Harrison ${ }^{1}$ and \\ Victoria J Orphan ${ }^{1}$ \\ ${ }^{1}$ Division of Geological and Planetary Sciences, California Institute, Pasadena, CA, USA; ${ }^{2}$ Monterey Bay \\ Aquarium Research Institute, Moss Landing, CA, USA and ${ }^{3}$ Department of Marine Sciences, University of \\ Georgia, Athens, GA, USA
}

\begin{abstract}
Aerobic methane oxidization in the pelagic ocean serves an important role in limiting methane release to the atmosphere, yet little is known about the identity and distribution of bacteria that mediate this process. The distribution of putative methane-oxidizing marine groups, OPU1, OPU3 and Group $X$, was assessed in different ocean provinces using a newly developed fingerprinting method (monooxygenase intergenic spacer analysis (MISA)) in combination with pmoA clone library analysis and quantitative PCR (qPCR). The distribution of these three distinct monooxygenase groups, previously reported from pelagic marine environments, was examined in 39 samples including active methane seeps in the Gulf of Mexico and Santa Monica Bay, submarine canyon heads along the California continental margin, an oligotrophic subtropical gyre and areas proximal to a hydrothermal vent in the North Fiji back-arc basin. OPU1 and OPU3 were widely and similarly distributed within the meso- and bathypelagic zone (110 to $\sim 2000 \mathrm{~m}$ water depth) and showed a $>50$-fold greater abundance near methane seeps relative to non-seep sites. In contrast, Group X was predominantly recovered from samples along the California margin, at both seep and non-seep sites. All three phylotypes were below detection in the epipelagic zone to depths of $100 \mathrm{~m}$. Several additional deeply branching monooxygenase sequences were also identified in this study, indicating the presence of uncharacterized groups of microorganisms potentially involved in the cycling of methane or ammonium.
\end{abstract}

The ISME Journal (2010) 4, 700-710; doi:10.1038/ismej.2009.155; published online 11 February 2010

Subject Category: microbial ecology and functional diversity of natural habitats

Keywords: methane seep; methanotroph; monooxygenase; pmo

\section{Introduction}

Aerobic methane oxidation in the ocean has been documented in a wide range of pelagic marine environments. Significant spatial variation in these rates exists, with elevated rates surrounding point sources for methane (for example, methane seeps and vents), and significantly lower rates in near-shore, continental margin and open-ocean environments (Ward et al., 1987; De Angelis et al., 1993, Holmes et al., 2000, Valentine et al., 2001). Estimates of the percentage of methane escaping from the ocean into the atmosphere are variable (Mau et al., 2007; Etiope et al., 2008; Solomon et al., 2009), and microorganisms that may consume methane in the water column are not yet well characterized. Together, these considerations indicate

Correspondence: PL Tavormina and VJ Orphan, Division of Geological and Planetary Sciences, California Institute of Technology, 1200 East California Boulevard, Mail Code 100-23, Pasadena, CA, 91125, USA.

E-mails: pattytav@gps.caltech.edu or vorphan@gps.caltech.edu Received 3 August 2009; revised 17 December 2009; accepted 17 December 2009; published online 11 February 2010 potential differences in the composition and spatial distribution of pelagic marine methanotrophs. Recent work has identified several putative aerobic methanotroph lineages potentially mediating methane turnover in different marine environments; however, spatial and temporal shifts in the composition of these aerobic methanotroph communities have not been examined.

Molecular studies aimed at identifying pelagic marine methanotrophs typically evaluate the metabolic gene marker particulate methane monooxygenase ( $p m o, \mathrm{pMMO}$ ), and three monooxygenase clades (OPU1, OPU3 and Group X) have been proposed to contribute to aerobic methane oxidation in the oceans (Hayashi et al., 2007; Jensen et al., 2008; Tavormina et al., 2008). The pMMO phylogeny for OPU1 and OPU3 suggests placement within the Gammaproteobacterial order Methylococcaceae; however, corresponding $16 \mathrm{~S}$ ribosomal RNA sequence has not been recovered for these groups despite efforts using multiple methanotrophtargeted primers (Tavormina et al., 2008). The third, deeply branching clade (Group X) is distinct from both pMMO and ammonia monooxygenase (AMO) 
(Tavormina et al., 2008). The OPU1, OPU3 and Group X clades are distinct from pMMO phylotypes that are commonly reported from methane-enriched marine sediments, suggesting that these organisms may be primarily adapted to a planktonic lifestyle, and potentially important consumers of methane in the marine water column (Tavormina et al., 2008; Wasmund et al., 2009).

To more clearly elucidate the distribution of planktonic aerobic methanotrophs across a range of oceanic settings, we used a PCR-based method targeting pmo that is sensitive and amenable to high-throughput sample analysis. This method (monooxygenase intergenic spacer analysis (MISA)) is based on the same principles as automated ribosomal intergenic spacer analysis (Fisher and Triplett, 1999), and a previously published fingerprinting method that identifies changes in ammoniaoxidizing populations in soil (Norton et al., 2002). MISA was used as a rapid screening tool to discern differences in the composition of methane monooxygenase genes from pelagic environments varying spatially as well as temporally. In addition, this technique was used in tandem with quantitative PCR (qPCR) and clone library analysis on select samples to assess the abundance and distribution of putative methanotroph lineages, OPU1, OPU3 and Group X, through diverse marine water column environments.

\section{Materials and methods}

Site description

Three biogeographically distinct water column environments spanning the epipelagic to bathypelagic zones were analyzed, including profiles above an active methane seep in the Gulf of Mexico (GoM), a near-shore submarine canyon off California (Partington Canyon (ParCyn)) and within the Atlantic oligotrophic gyre (Bermuda Atlantic Time Series (BATS)). GoM samples were collected from 50 to $530 \mathrm{~m}$ below sea level (mbsl) above a methane seep in block GC185 (GoM GC185). Oil-stained sediments and gas hydrates are common at this site (Joye et al., 2004; Solomon et al., 2008) and methane concentrations are elevated throughout the water column. Samples from the head of Partington Canyon, located $\sim 3.5 \mathrm{~km}$ from shore, were collected from 1.8 to $525 \mathrm{mbsl}$. This submarine canyon is situated in an iron-limited coastal upwelling region of the central California margin (Bruland et al., 2001) and has limited freshwater inflow and a narrow continental shelf. Active methane seepage has not been located in the region; however, elevated methane concentrations have been measured in the lower portion of the water column. BATS samples spanning a range of 0-300 mbsl were surveyed in both spring and fall. Although methane concentrations are not routinely measured in the BATS, similar nutrient-poor openocean sites report methane levels typically below
$3 \mathrm{nM}$ in the upper $300 \mathrm{~m}$ of the water column (Jones, 1991; Seifert et al., 1999; Holmes et al., 2000).

In addition to targeted depth profiles, MISA was also used to survey monooxygenase genes in select benthic water samples from multiple submarine canyon sites along the California continental margin (Partington Canyon, Monterey Canyon, Año Nuevo Canyon and Pioneer Canyon), above an active methane seep on the flank of the Santa Monica Basin (SMB; $33^{\circ} 47.9748^{\prime} \mathrm{N} 118^{\circ} 38.796^{\prime} \mathrm{W}$ ) (Tavormina et al., 2008), and sites adjacent to a white smoker hydrothermal vent in the North Fiji back-arc basin. Methane concentrations were not measured from this hydrothermal vent; however, a hydrothermal vent field in the North Fiji back-arc basin has previously been shown to contain elevated, yet variable, levels of geologically sourced methane, ranging from low $\mathrm{nM}$ to $\mu \mathrm{M}$ range (Podgorsek et al., 2004).

\section{Sample collection}

Water column samples from submarine canyon environments along the California continental margin were collected in April 2006 by CTD (conductivity, temperature, depth) cast from the R/V Western Flyer. In all, $10 \mathrm{l}$ samples were collected from selected depths in Niskin-style bottles. Additional targeted samples collected near the sea floor were obtained using $5 \mathrm{l}$ Niskin bottles mounted on the remotely operated vehicle Tiburon. Immediately after sample recovery, $240 \mathrm{ml}$ subsamples were taken for methane concentration analysis as described in Tavormina et al. (2008). The remaining contents of each bottle were drained into separate polycarbonate carboys and kept at $\sim 4{ }^{\circ} \mathrm{C}$ until filtration, which occurred as soon as possible after collection. Water samples (1-2 l) were vacuum filtered through $47 \mathrm{~mm}$ Durapore filters (pore size $=0.2 \mu \mathrm{m}$; Millipore, Billerica, MA, USA). Filters were rinsed with filtered deionized water, flash frozen in liquid $\mathrm{N}_{2}$ and stored dry at $-80^{\circ} \mathrm{C}$ until further processing. Water column samples from the North Fiji back-arc basin were collected in May 2005, using 2.1 l Niskin bottles mounted on the remotely operated vehicle Jason (dive J2_150). Samples were collected within and adjacent to a white smoker anhydrite chimney named 'Ivory Tower' ( $16^{\circ} 59.3 \mathrm{~S}$; $173^{\circ} 54.9 \mathrm{E}$; $\sim 1972 \mathrm{mbsl}$ ). Temperatures were recorded using a heat flow probe at the base of the chimney $\left(86.0^{\circ} \mathrm{C}\right)$ and in a neighboring Bathymodiolus mussel bed $\left(13.6^{\circ} \mathrm{C}\right)$. Targeted water column samples were collected from the hydrothermal vent plume, in diffuse flow near the base of the chimney and above an adjacent mussel bed. Samples (1-2 l) were filtered onto $47 \mathrm{~mm}$ Durapore filters (pore size $=0.2 \mu \mathrm{m}$ ) and stored at $-80^{\circ} \mathrm{C}$ in $1 \mathrm{ml}$ of sucrose-based lysis buffer as described in Delong (1992). For GoM GC185, water samples were collected from a methane plume during a July 2002 cruise by positioning the rosette within the plume using Chirp Sonar and tripping bottles during transit from the bottom to the surface. One or two $10 \mathrm{l}$ Go-flow bottles were tripped at each 
depth. Upon recovery, oxygen and methane concentrations and temperature were measured and subsamples were aliquoted for methane oxidation rates as described in Carini et al. (2005). In addition, $1 \mathrm{l}$ of water from each depth was filtered through a Sterivex filter (Millipore, Billerica, MA, USA) that was frozen at $-20^{\circ} \mathrm{C}$ when shipboard and subsequently stored at $-80^{\circ} \mathrm{C}$. Samples collected from the BATS and the SMB methane seep have been reported in Steinberg et al. (2001) and Tavormina et al. (2008). BATS samples were collected from eight depths (0-300 mbsl) in September 1997 (cruise 10108) and March 1998 (cruise 10114).

\section{DNA extraction}

DNA was extracted as described previously (Tavormina et al., 2008) with a final purification step using small-scale cesium chloride density gradient centrifugation as described in Delong (1992). DNA was quantified using Picogreen assay according to the manufacturer's instructions (Invitrogen, Carlsbad, CA, USA). Final extraction volume was typically $200 \mu \mathrm{l}$ and DNA concentration ranged from 0.3 to $3 \mu \mathrm{g} \mathrm{ml}^{-1}$.

\section{Primer design}

To obtain the native sequence of the $3^{\prime}$ end of $p m o C$ from representatives of OPU1, OPU3 and Group X, a degenerate primer (pmoC364f, 5'-TWCTTYACM GRGCARGAYG-3') targeting pmoC position 364-382 was paired with reverse primers specific to either OPU1 and OPU3 (pmoAwc661r, Tavormina et al., 2008; and pmoAwc377r, 5'-AAGTTGAAG TAWCKGTTAATCCA-3'), or to Group X (pmoA682r, Holmes et al., 1995; and novel pmoA634r, Tavormina et al., 2008). A semi-nested amplification from SMB methane seep DNA recovered an $\sim 1-\mathrm{kb}$ band for each phylotype, which was cloned using the pGEM-T easy cloning kit (Promega, Madison, WI, USA) and sequenced. This strategy recovered fragments spanning the $3^{\prime}$ end of pmoC, the intergenic region and the $5^{\prime}$ end of $p m o A$. These $p m o C-p m o A$ reference sequences were aligned with representative proteobacterial pmo operon sequences, and two highly conserved sites flanking the noncoding spacer were targeted for primer design (Table 1). The fluorescent tag Well-redD1 (Sigma-Aldrich, St Louis MO, USA) was added to primer spacer pmoC626f for visualization of PCR product in capillary electrophoresis.

\section{Amplification and length determination}

Routine amplifications using $0.3-1 \mathrm{ng}$ of environmental DNA template were performed as described previously (Tavormina et al., 2008), using primers, annealing temperatures and cycling conditions described in Supplementary Table 1. For MISA, primers spacer_pmoC606f and spacer_pmoA189r were paired to enrich target sequences (20 cycles). This $20 \mu \mathrm{l}$ product was diluted to $100 \mu \mathrm{l}$ with $10 \mathrm{mM}$ Tris-HCl pH 8.0, and $2 \mu \mathrm{l}$ was used in a second round of semi-nested amplification using fluorescent primer spacer_pmoC626f paired with primer spacer_pmoA189r (25 cycles; Supplementary Table 1). Semi-nested amplification was necessary to improve specificity for the pmo spacer in samples in which the target was in low abundance (less than $\sim 200$ copies per ng environmental DNA, typical of non-methane seep environments). Approximately $100 \mathrm{ng}$ of fluorescent PCR product was precipitated and separated through capillary electrophoresis as described for terminal restriction fragment length polymorphism analysis in Goffredi et al. (2008). Electropherogram peaks were analyzed in a targeted range ( $\sim 400-650$ base pairs (bp)), as determined by the in silico and empirical spacer lengths of OPU1, OPU3, Group X and spacer lengths from currently described cultured organisms (Table 1).

\section{MISA assay development}

MISA methodology was validated on reference clones (OPU1, OPU3 and Group X), genomic DNA from cultured methanotrophic and ammonia-oxidizing proteobacteria and a previously characterized environmental sample from the Santa Monica Bay (Table 1, Supplementary Figure 1, Figure 1e). Assay conditions were chosen that detected each of the reference clones without affecting overall product yield and quality, as determined in mixed template assays (Supplementary Table 1 and Supplementary Figure 1). These conditions reliably amplified from a minimum of 50 copies of initial target sequence, and generated OPU3 and Group X product levels to within $80-120 \%$ of their initial relative abundance. Some primer bias, possibly resulting from the use of degenerate primers, was evident against OPU1, in which product levels achieved only $\sim 35 \%$ of initial relative abundance (Supplementary Figure 1). As such, detection of OPU1 by the MISA assay may represent a minimum estimate.

Using the MISA primer set, PCR products were successfully generated from all cultured organisms tested. Length determination for six of these amplicons was within $4 \mathrm{bp}$ of the predicted in silico length (Table 1). Methylosinus trichosporium and Nitrosococcus oceani, which encode longer intergenic spacers, deviated from in silico predicted length by 11 to $15 \mathrm{bp}$ (Table 1). In general, known methanotrophic lineages from marine environments could be distinguished from these cultured representatives by spacer length; however, the potential overlap in spacer length between members of the genus Methylomicrobium and the uncultured Group X necessitated additional validation of the Group X peak position through cloning and sequencing. A proof-of-concept environmental screen was performed on DNA extracted from the SMB methane seep plume, which was previously shown to contain 


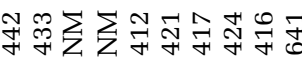

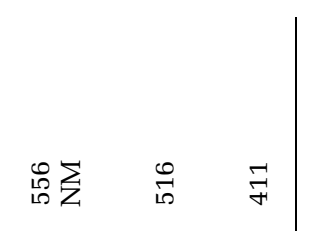

703
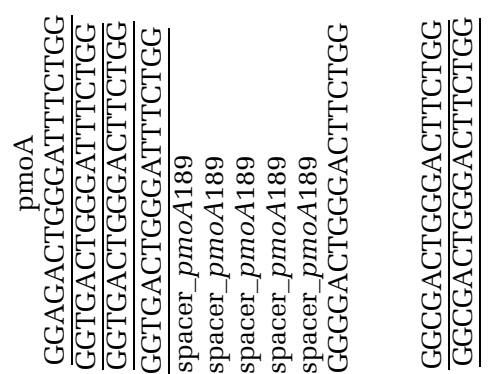

U

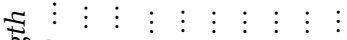

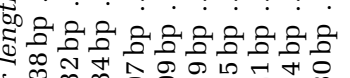

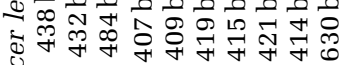

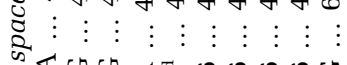

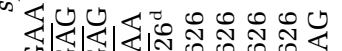

过

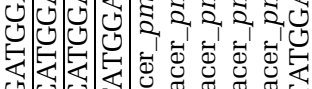

步

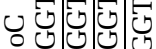

घ:
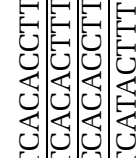

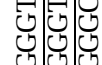

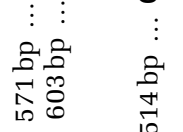

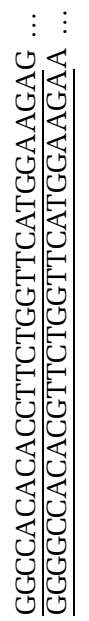

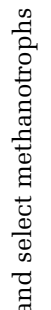

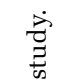

$\stackrel{\infty}{\ddagger}$

$\begin{array}{lll}x & 5 \\ 2 & 0 & 0\end{array}$

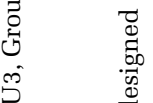

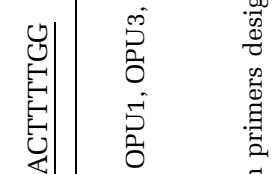

包 豆 节

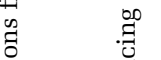

总

.

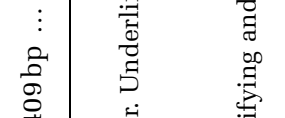

¿

$\vdots$

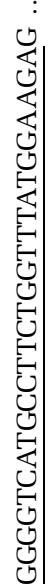

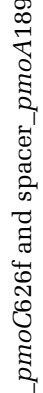

荘

s

营

ฮี

3

ชิ

ฐ

悹热

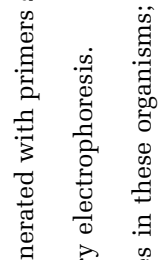

要

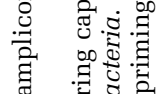

命

余荅

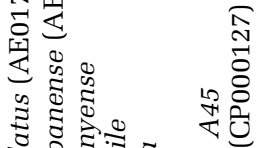

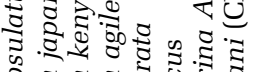

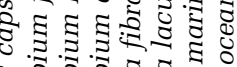

3.

证.

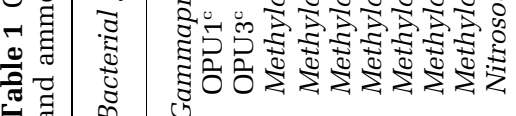

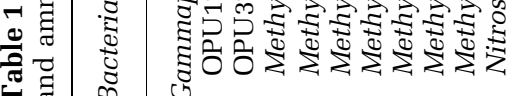

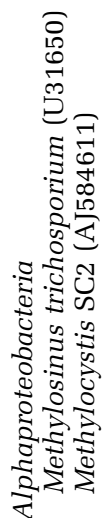

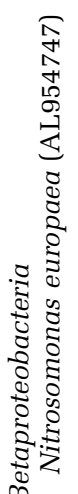

ส

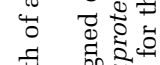

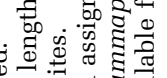

च

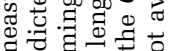

을

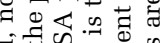

$\sum .90$

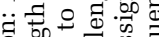

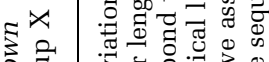

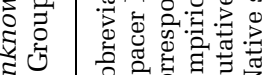


704

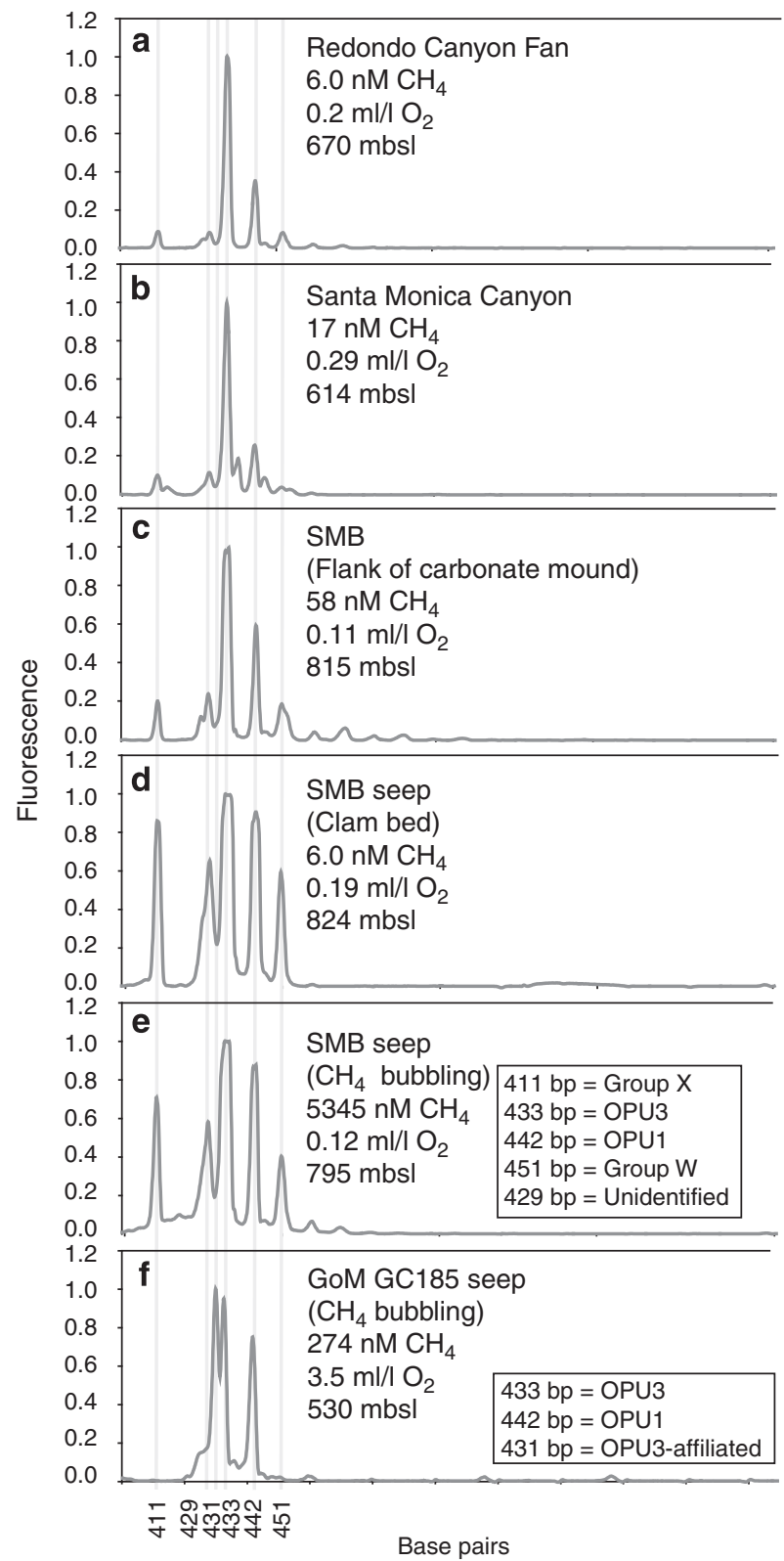

Figure 1 Environmental MISA electropherograms, Santa Monica Basin methane seep (panels a-e) and Gulf of Mexico GC185 methane seep (panel f). OPU1, OPU3 and Group X were detected in the SMB using MISA. Additional peaks detected throughout the Santa Monica basin include Group W (451bp) and an unidentified sequence (429bp). At GoM GC185, OPU1 and OPU3 were detected, as was an OPU3-affiliated peak (OPU3 (431 bp)).

monooxygenase clades OPU1, OPU3 and Group X (Tavormina et al., 2008). MISA successfully detected these groups as evidenced by fragment lengths of 442, 433 and $411 \mathrm{bp}$, respectively (Figure 1e and Table 2). Terminal restriction fragment length polymorphism analysis of the SMB MISA amplification product using restriction enzymes NcoI and HincII corroborated the MISA results, and verified that the single peaks observed in MISA corresponded to single phylotypes (data not shown). pmo library construction sequencing and analysis Clone library construction and sequencing were performed using primers described in Supplementary Table 1 and the methods described in Tavormina et al. (2008). A total of 48 clones were analyzed from samples obtained in the following environments: a methane seep plume in SMB $(795 \mathrm{mbsl})$, a methane seep in the GoM GC185 $(530 \mathrm{mbsl})$ and an epipelagic methane maximum $(200 \mathrm{mbsl})$ and methane-enriched benthic water $(524 \mathrm{mbsl})$ in Partington Canyon. Clones with inserts of the expected size were selected for restriction fragment length polymorphism and sequence analysis. Clones showing $96 \%$ sequence identity were considered to belong to the same operational taxonomic unit. Predicted pMMO-A sequences were trimmed to residues 5-49 ( $M$. capsulatus numbering) and aligned in MacClade. Alignments were exported to MEGA v.4 (Tamura et al., 2007) to generate the phylogeny, using total character difference to estimate evolutionary distance. A neighbor-joining phylogeny was constructed using 5000 bootstrap replicates to assign confidence levels to nodes (neighbor-joining/parsimony). Crenarchaeotal AMO-A sequences were omitted in this phylogeny to better visualize the relationships between OPU1, OPU3 and Group X. pMMO-A sequence from the Gammaproteobacterial lineage Crenothrix was not included, because the sequence of residues 5-49 is unavailable for this lineage. Sequences obtained in this study have been assigned GenBank accession numbers GQ376540-GQ376548.

\section{$5^{\prime}$ exonuclease (Taqman) assay}

A qPCR assay (Taqman) was developed using Primer Express v2.0 (Applied Biosystems, Foster City, CA, USA) for the OPU3 clade, based on available published OPU3-related sequences ( $>96 \%$ identity, accession numbers AB276027, EU444844 and EU444875). Primer and probe sequences are listed in Table 2 and were used at the following final concentrations: $1 \mu \mathrm{M}$ forward primer, $1.5 \mu \mathrm{M}$ reverse primer and $200 \mu \mathrm{M}$ of the Taqman probe labeled with 6-carboxyfluorescein (FAM, 5') and a black hole quencher (BHQ, $3^{\prime}$ ). This assay targets the relatively conserved internal $\mathrm{pmo} A$ coding sequence available for OPU3 (Hayashi et al., 2007; Tavormina et al., 2008). As such, the assay may not reliably enumerate OPU3 representatives in other environments, if significant sequence divergence has occurred. In particular, internal $p m o A$ sequence is not available for newly described OPU3-related phylotypes in this study and the efficiency of the qPCR assay on these phylotypes is currently untested. Quantitative PCR was performed on a 7300 real-time PCR system (Applied Biosystems) using a two-step PCR $\left(94^{\circ} \mathrm{C}\right.$ for $15 \mathrm{~s}$ and $57^{\circ} \mathrm{C}$ for $60 \mathrm{~s}$ ) for 40 cycles. Standard curve analysis on cesium chloridecleaned linearized OPU3 plasmid template (clone ERBWC_12C, accession number EU444875) 


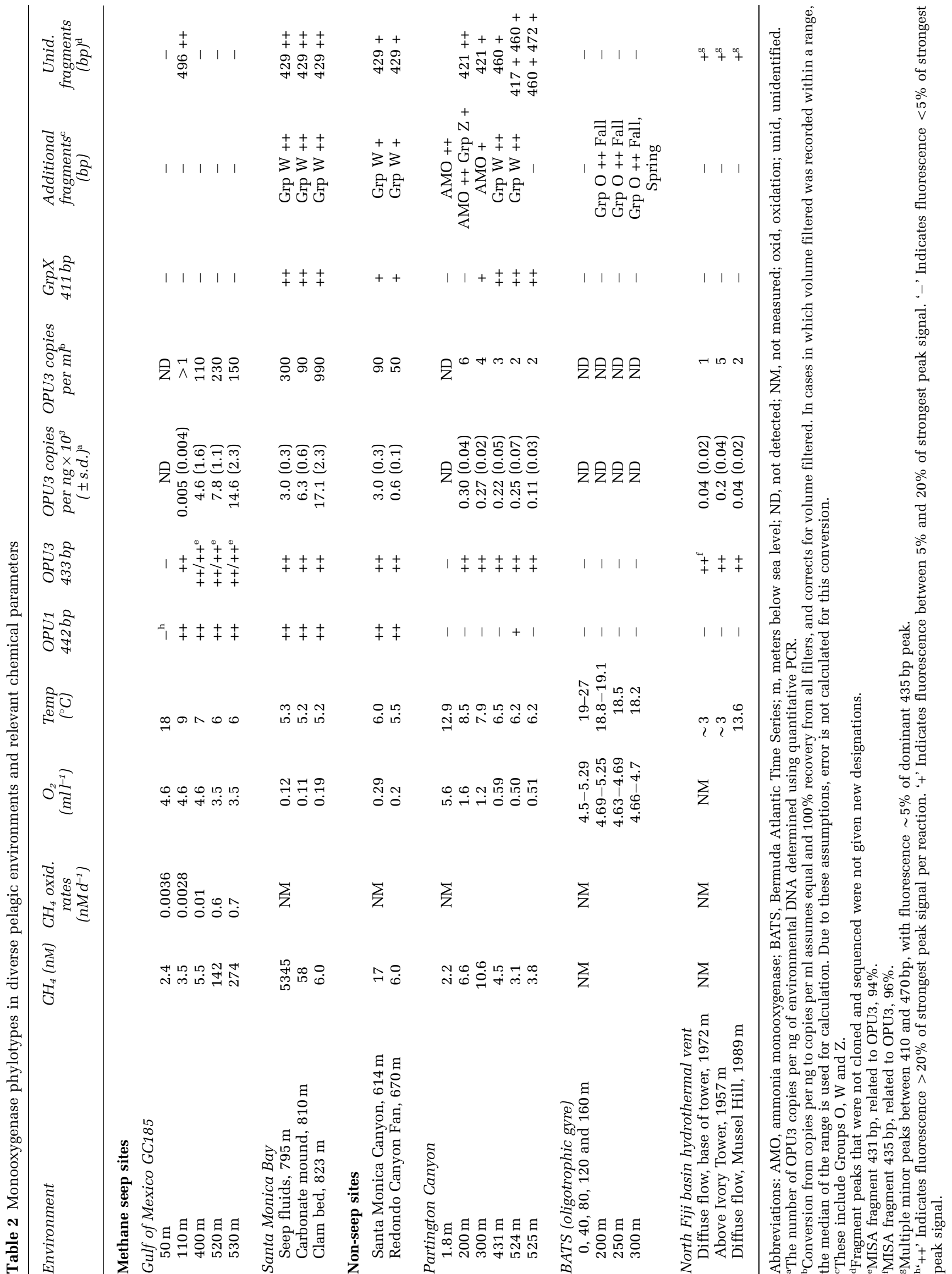




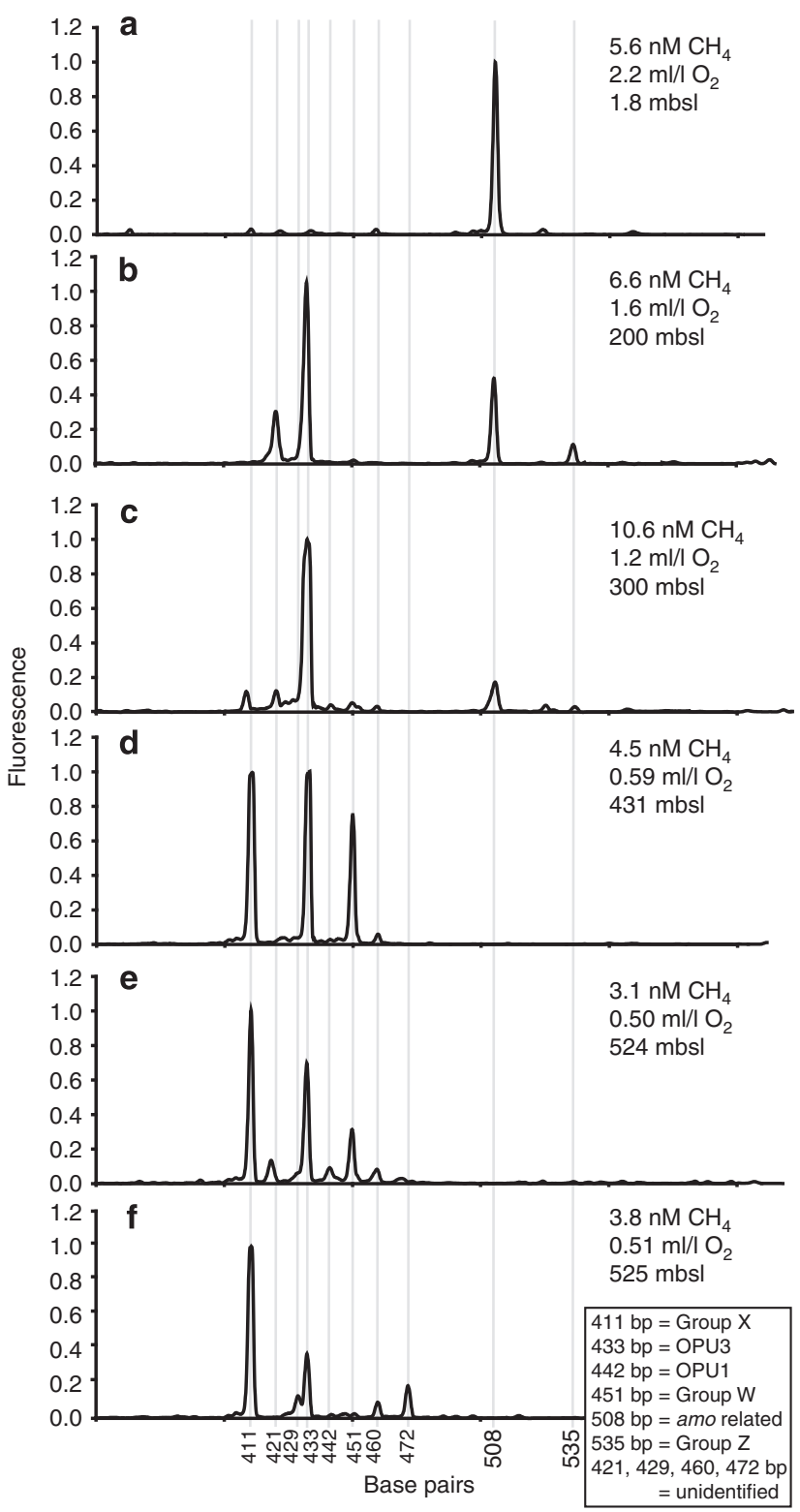

Figure 2 MISA electropherograms from a depth profile in Partington Canyon, an iron-limited upwelling non-seep site (1.8 mbsl to $525 \mathrm{mbsl}$ ). OPU3, Group X and Group W were detected at and below $300 \mathrm{mbsl}$ (panels c-f); OPU3 was also present at $200 \mathrm{mbsl}$ (panel b). OPU1 was present at $524 \mathrm{mbsl}$ (panel e). Additional peaks detected include Group Z (535 bp. at $200-300 \mathrm{mbsl}$, panels $\mathbf{b}$ and $\mathbf{c}$ ), a Betaproteobacterial amo sequence (508 bp, 1.8-300 mbsl, panels a-c) and an unidentified sequence ( $421 \mathrm{bp}$ at depths between 200 and $300 \mathrm{mbsl}$, panels b and $\mathbf{c}$; and 429, 460 and 472 bp at $525 \mathrm{mbsl}$, panel f).

indicated a minimum detection limit of 20 copies of target DNA, and amplification efficiency of $>95 \%$. However, degeneracies in primers and probe may lead to lower effective primer and probe concentrations when assaying environmental extracts. Twofold serial dilutions of cesium chloride-cleaned environmental DNA were used in the qPCR assay to identify the linear working range (typically corresponding to 2- to 16 -fold dilutions). Five replicates within this range were quantified and the average and $1-\sigma$ s.d. of these measurements were calculated.

\section{Results and discussion}

Distribution of OPU1, OPU3 and Group X associated with deep-sea methane seeps

The flank of the SMB on the California continental margin harbors a well-characterized carbonate mound and methane seep system (Normark and Hein, 2003; Ussler et al., 2006). Screening of samples collected within the methane plume revealed MISA peaks belonging to clades OPU1, OPU3 and Group X, in agreement with previous clone library analysis (Tavormina et al., 2008). Two unique peaks (429 and $451 \mathrm{bp}$ ) were also present (Figure 1e), one of which $(451 \mathrm{bp})$ was identified in a corresponding clone library as a divergent monooxygenase (termed Group W) with a phylogenetic placement between AMO and pMMO (Figures 1 and 3). Group W was not previously recovered in SMB clone libraries, suggesting that the newly designed pmo primers can recover additional monooxygenase gene diversity in the ocean.

To determine the lateral distribution of putative methanotrophs surrounding the SMB methane seep, benthic water column samples were probed for OPU1, OPU3, Group X and Group W. A spatially distributed set of samples, including samples from the flank of the SMB carbonate mound $(\sim 57 \mathrm{nM}$ $\mathrm{CH}_{4}$ ) and an adjacent chemosynthetic clam bed (5.6 $\mathrm{nM} \mathrm{CH}_{4}$ ), Santa Monica Canyon ( $\sim 10 \mathrm{~km}$ northeast of the mound, $16.7 \mathrm{nM} \mathrm{CH}_{4}$ ) and the Redondo Canyon Fan (southeast of the mound, $5.6 \mathrm{nM} \mathrm{CH}_{4}$ ) were analyzed using MISA. Peaks affiliated with OPU1, OPU3, Group X, Group W and the as-yetunidentified 429-bp fragment were detected throughout Santa Monica Bay; however, the relative abundance of phylotypes varied between sites (Figure 1). Distal to the active methane seep, OPU3 represented the major peak, with OPU1 detected at lower abundance, and peaks corresponding to Group W and Group X only slightly above background (Figures 1a and b). In comparison, sites directly associated with the methane seep seemed to support a more complex methane monooxygenase community, indicated by the relative height of the MISA peaks for OPU1, OPU3, Group X and Group W (Figures 1c-e). Previously, clone libraries from the SMB vent fluids recovered OPU1 and OPU3 in roughly equal numbers (77 and 63 clones, respectively), consistent with the MISA electropherograms generated in this study (Tavormina et al., 2008).

Vertical distribution of monooxygenases above a methane seep in the GoM. Depth-related differences in monooxygenase community composition were assessed above a well-characterized methane 


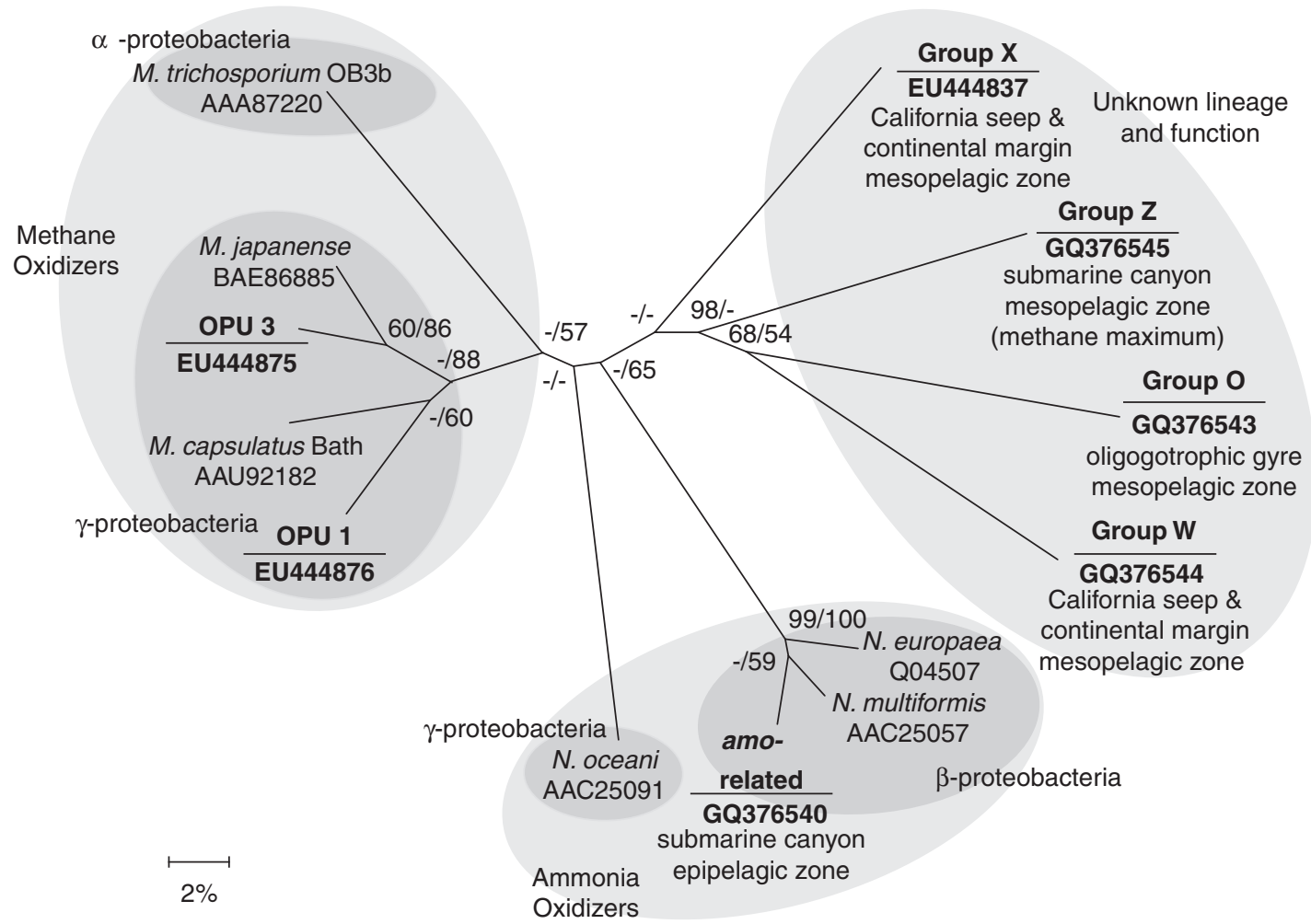

Figure 3 Phylogeny of predicted AMO-A and pMMO-A sequences from sites in this study (amino acid residues 5-49). Sequences identified in this study are indicated in bold. Confidence levels above $50 \%$ are reported at the nodes (5000 replicates neighbor joining, 5000 replicates parsimony).

seep in the GoM (block GC185, $546 \mathrm{mbsl}$ ). At this site, methane concentrations spanned two orders of magnitude, from $274 \mathrm{nM}$ near the seep $(530 \mathrm{mbsl}$, $\sim 16 \mathrm{~m}$ above sea floor) to $2.4 \mathrm{nM}$ in the epipelagic zone $(50 \mathrm{mbsl})$. Correspondingly, aerobic methane oxidation rates were highest near the methane seep $\left(0.7 \mathrm{nM} \mathrm{l}^{-1}\right.$ day $^{-1}$ at $\left.530 \mathrm{mbsl}\right)$ and significantly lower at $50 \mathrm{mbsl}\left(0.0036 \mathrm{nMl}^{-1} \mathrm{day}^{-1}\right.$, Table 2). MISA profiles indicate the presence of OPU3 (433 bp) and OPU1 (442 bp) immediately overlying the seep (530 mbsl, Figure 1f), as well as at 110, 400 and $520 \mathrm{mbsl}$, but not at $50 \mathrm{mbsl}$ (Table 2). A third peak (431 bp) was detected in deep-water samples (400-530 mbsl, Figure $1 \mathrm{f}$ and Table 2). The identities of these fragments were verified by cloning and sequencing the MISA amplicon from the $530 \mathrm{mbsl}$ sample. The 431-bp fragment is related to the OPU3 clade ('OPU3 (431 bp)'; 94\% identical to the OPU3 reference sequence and $96 \%$ amino acid similarity). The presence of $p m o A$ phylotypes OPU1 and OPU3 through mid- to deep water above GoM GC185 is consistent with the interpretation that these phylotypes participate in methane oxidation.

\section{Distribution of OPU1, OPU3 and Group X in non-seep sites}

The composition of monooxygenase-bearing communities was analyzed from six depths in Partington
Canyon, California, ranging from 0 to $200 \mathrm{mbsl}$ (epipelagic zone), $300 \mathrm{mbsl}$ (a local methane maximum zone) and 431-525 mbsl (low oxygen zone). MISA analysis revealed variations between different depth horizons in the water column. Community composition within and immediately below the epipelagic zone was distinct from that below the local methane maximum, with samples collected above $300 \mathrm{mbsl}$ characterized by a 508-bp fragment affiliated with a Betaproteobacterial-associated AMO sequence (Figures 2a-c and 3 and Table 2).

OPU3 and Group X fragments were detected below the epipelagic zone $(>200 \mathrm{~m}$, Figures $2 \mathrm{~b}-\mathrm{f})$, and OPU1 was detected at low relative abundance at $524 \mathrm{mbsl}$. Clone library construction from the $524 \mathrm{~m}$ depth confirmed the identification of these groups. Additional monooxygenase phylotypes were observed within and below the local methane maximum in Partington Canyon (200-300 mbsl). Group W (451 bp; 98\% similar to the SMB phylotype) was recovered at $\geqslant 431 \mathrm{mbsl}$ (Figures $2 \mathrm{~d}$ and e, and 3). A 535-bp MISA peak was detected at low abundance within the methane maximum (Figures $2 b-c)$ and was found to encode another deeply diverged monooxygenase termed Group Z (Figure 3). Overall, waters below the local methane maximum (431-530 mbsl) were more similar to one another in terms of monooxygenase composition, than to samples collected within the local methane maximum 
(200-300 mbsl) and within the epipelagic zone (1.8 mbsl) (Supplementary Figure 2).

A survey of bottom waters of neighboring submarine canyons along the Central California continental margin revealed the presence of OPU1, OPU3, Group X and Group W (Supplementary Figures 2 and 3). MISA peak heights suggest variable abundance of these phylotypes in near-seafloor samples from Pioneer Canyon (1120 mbsl, 0.24 nM methane), Año Nuevo Canyon (574 mbsl, $2.1 \mathrm{nM}$ methane) and Monterey Canyon (559 mbsl, $3.8 \mathrm{nM}$ methane), and the detection of OPU1 and OPU3 along the Central California continental margin is consistent with reports of these phylotypes outside of active methane seep environments (Hayashi et al., 2007; Jensen et al., 2008), suggesting that they comprise a broadly-distributed methane sink in the deep ocean that may consume trace levels of methane leaking out of the sea floor or produced in situ.

Vertical distribution of monooxygenases in an oligotrophic open-ocean system. The occurrence of OPU1, OPU3 and Group X monooxygenase sequences in open-ocean oligotrophic environments was assessed using samples from the Sargasso Sea. Depth profiles $(0-300 \mathrm{mbsl})$ from September and March were collected at the BATS station and screened with MISA. Diagnostic peaks representing OPU1, OPU3 and Group X were not detected. Instead, a single 730-bp product was recovered from depths between 200 and $300 \mathrm{mbsl}$ in September and from $300 \mathrm{mbsl}$ in March. This fragment encodes another deeply branching member of the AMO/ pMMO superfamily, termed Group O (Table 2 and Figure 3). Whether Group $\mathrm{O}$ has a role in methane or ammonia oxidation remains to be determined; however, these results suggest that the monooxygenase community of the oligotrophic ocean system may be distinct from continental margin-affiliated and deep-water habitats.

Community composition of monooxygenases in the North Fiji back-arc basin. Hydrothermal vents provide another deep point source for methane in the ocean, and enhanced aerobic methane oxidation has been recorded in hydrothermal vent plumes (De Angelis et al., 1993). Initial pmoA surveys associated with these habitats have recovered evidence of type I Gammaproteobacterial methanotrophs from sites along the Mid-Okinawa trough and Mid-Atlantic Ridge (Elsaied et al., 2004).

Water samples from three areas within the North Fiji vent field were screened by MISA for the occurrence of OPU1, OPU3 and Group X phylotypes. These samples comprised the plume of the anhydrite-dominated white smoker 'Ivory Tower' $(\sim 2000 \mathrm{mbsl})$, an adjacent zone of diffuse flow, and shimmering water above a neighboring mussel bed. The MISA monooxygenase peaks commonly recovered in other bathypelagic environments were not detected in these samples; rather, all three habitats contained a prominent 435-bp peak (Table 2). Direct sequencing of this amplicon revealed that that belongs to the OPU3 clade ('OPU3 (435 bp)'; 96\% identity to the OPU3 reference phylotype and $100 \%$ amino acid similarity). These findings illustrate that although members of the OPU3 clade seem widely distributed across a range of marine habitats, there is site-specific or habitat-related variation within this monooxygenase lineage.

\section{Quantification of the OPU3 clade}

Members of the OPU3 clade were the most broadly distributed of the three monooxygenase groups targeted in this study. To quantify the abundance of this clade through the different sampling sites, a real-time $5^{\prime}$ exonuclease (TaqMan) assay was developed for this group. Members of OPU3 were found to be most abundant adjacent to methane seeps, exceeding 10000 copies per ng total DNA (Table 2).

At GoM GC185 (530 mbsl), OPU3 abundance was 15000 copies per ng DNA, or $\sim 200$ copies per ml seawater, assuming $100 \%$ recovery during DNA extraction. At shallower depths, OPU3 abundance was significantly less, measuring $\sim 4600$ copies per ng DNA at $400 \mathrm{mbsl}$, and $\sim 5$ copies per ng DNA at $110 \mathrm{mbsl}$, corresponding with the lower methane concentrations and oxidation rates measured at these depths (Table 2). OPU3 abundance was also elevated adjacent to the SMB seep, with 17000 copies per ng DNA above the clam bed adjacent to the seep, and 600-3000 copies per ng DNA in deep-water samples distal to the seep (Santa Monica Canyon and Redondo Canyon Fan, 614 and $670 \mathrm{mbsl}$, respectively). A lower abundance (40-300 copies per ng DNA, or less than 10 copies per $\mathrm{ml}$ seawater) was measured in the non-seep submarine canyon systems along the California margin (Table 2). Within hydrothermal vent fluids from the North Fiji back-arc basin, similar low abundance of OPU3 was recorded, although the efficiency of the qPCR assay has not been tested directly on the OPU3 $(435 \mathrm{bp})$ phylotype recovered from this environment, and additional tests are necessary to confirm its abundance. As observed using MISA, OPU3 abundance was below detection at BATS, as well as in surface waters of Partington Canyon and GoM GC185. Overall, OPU3 was detected at $9800 \pm 5900$ copies per ng DNA in the five samples in this study adjacent to methane seeps (within $50 \mathrm{~m}$ of active methane venting), and only $140 \pm 130$ copies per ng DNA in samples collected from sites with no known seep influence (Partington Canyon and neighboring canyon sites, and upper water column at BATS and GoM GC185). The elevated OPU3 abundance proximal to seeps relative to non-seep sites $(P=0.022$, Welch's $t$-test) supports the interpretation that members of this clade are bona fide methane oxidizers, 
consistent with their phylogenetic placement within Methylococcaceae.

\section{Summary}

This study describes the application of a newly developed PCR-based assay (MISA) to assess the distribution of putative aerobic methanotrophs in diverse marine pelagic environments. MISA complements existing pmo profiling methods including terminal restriction fragment length polymorphism and microarray analyses (Bodrossy et al., 2003; Horz et al., 2005; Qiu et al., 2008) by targeting an intergenic spacer within the pmo operon. Variations in amplicon length are determined directly without requiring downstream manipulations (for example, digestion and hybridization). MISA provides sensitivity and high-throughput detection of low-abundance marine monooxygenases, to facilitate large-scale studies of monooxygenase composition in the environment. When coupled with concentration and turnover rate measurements of metabolic substrates, and combined with techniques such as qPCR and clone library analysis of targeted samples, a fuller picture of the dynamics of marine monoxygenases in response to a changing physicochemical environment is possible.

Our analyses indicate that lineages OPU1, OPU3 and Group X are present below $200 \mathrm{mbsl}$ in a variety of methane seep and non-seep sites along the California continental margin, within the GoM, and within a hydrothermal vent field in the North Fiji basin. In combination with reports of OPU1 and OPU3 in the Pacific OMZ, and OPU1 in a coral reef environment in Norway (Hayashi et al., 2007; Jensen et al., 2008), this study shows broad distribution of OPU1 and OPU3, and to a lesser extent Group X, below the mixed layer.

These proteobacterial-related pmo sequences are more abundant in deeper waters than in the euphotic zone, which may relate to vertical zonation of functional capabilities of microbial assemblages through the ocean's interior (DeLong et al., 2006). Surface waters from Partington Canyon and GoM GC185 are characterized by low methane concentrations and methane oxidation rates are typically lower in the epipelagic zone (Table 2, Ward et al., 1987; De Angelis et al., 1993; Holmes et al., 2000; Valentine et al., 2001), trends that are consistent with the distributions of OPU1 and OPU3 presented in this study. The physico-chemical environment of surface waters (temperature, light and nutrients) and ecological pressures from photosynthetically active microorganisms, are distinct from the mesopelagic zone, and may contribute to the observed distributions of OPU1 and OPU3.

Members of the OPU3 clade were represented by three distinct MISA fragments (431, 433 and $435 \mathrm{bp}$ ), two of which associated with specific environments (OPU3 (431 bp) detected at GoM GC185, and OPU3 (435 bp) detected in a hydrothermal vent system). In addition, the recovery of deeply branching monooxygenases from different ocean provinces illustrates that broad monooxygenase diversity is present in the ocean. Future studies monitoring these monooxygenase lineages can be facilitated by high-throughput methods such as MISA. Such surveys, in addition to investigations incorporating physical parameters and detailed chemical and rate measurements, as well as efforts to link SSU ribosomal gene sequence to putative methanotrophs OPU1, OPU3 and Group X, will be essential for further elucidating the dynamics of aerobic methane oxidation in the ocean.

\section{Acknowledgements}

We thank Mary Lidstrom, Dan Arp and Martin Klotz for reference strains, Steve Giovannoni's group for BATS DNA, Bob Vrijenhoek for the Fiji/Lau expedition and Shana Goffredi, Olivia Mason, and 3 anonymous reviewers for assistance, critical comments, and improving the quality of this study. Support was provided by NASA (NNG06GB34G to VJO), NSF (MCB-0348492 to VJO and OCE-0085549 to SBJ), the Gordon and Betty Moore Foundation (to VJO) and the David and Lucile Packard Foundation (to WU).

\section{References}

Bodrossy L, Stralis-Pavese N, Murrell JC, Radajewski S, Weilharter A, Sessitsch A. (2003). Development and validation of a diagnostic microbial microarray for methanotrophs. Environ Microbiol 5: 566-582.

Bruland KW, Rue EL, Smith GJ. (2001). Iron and macronutrients in California coastal upwelling regimes: implications for diatom blooms. Limnol Oceanogr 46: 1661-1674.

Carini S, Bano N, LeCleir G, Joye SB. (2005). Aerobic methane oxidation and methanotroph community composition during seasonal stratification in Mono Lake, California (USA). Environ Microbiol 7: 1127-1138.

De Angelis MA, Lilley MD, Baross J. (1993). Methane oxidation in deep sea hydrothermal plumes of the endeavor segment of the Juan de Fuca Ridge. Deep Sea Res (1 Oceanogr Res Pap) 40: 1169-1186.

Delong EF. (1992). Archaea in coastal marine environments. Proc Natl Acad Sci USA 89: 5685-5689.

DeLong EF, Preston CP, Mincer T, Rich V, Hallam SJ, Frigaard N-U et al. (2006). Community genomics among stratified microbial assemblages in the ocean's interior. Science 311: 496-503.

Elsaied HE, Hayashi T, Naganuma T. (2004). Molecular analysis of deep-sea hydrothermal vent aerobic methanotrophs by targeting genes of $16 \mathrm{~S}$ rRNA and particulate methane monooxygenase. Mar Biotechnol (NY) 6: 503-509.

Etiope G, Lassey KR, Klusman RW, Boschi E. (2008). Reappraisal of the fossil methane budget and emission from geologic sources. Geophys Res Lett 35: L09307.

Fisher MM, Triplett EW. (1999). Automated approach for ribosomal intergenic spacer analysis of microbial diversity and its application to freshwater bacterial communities. Appl Environ Microbiol 65: 4630-4636. 
Goffredi SK, Wilpiszeski R, Lee R, Orphan VJ. (2008). Temporal evolution of methane cycling and phylogenetic diversity of archaea in sediments from a deepsea whalefall in Monterey Canyon, California. ISME J 2: 204-220.

Hayashi T, Obata H, Gamo T, Sano Y, Naganuma T. (2007). Distribution and phylogenetic characteristics of the genes encoding enzymes relevant to methane oxidation in oxygen minimum zones of the eastern Pacific Ocean. Res J Environ Sci 1: 275-284.

Holmes AJ, Costello A, Lidstrom ME, Murrell JC. (1995). Evidence that particulate methane monooxygenase and ammonia monooxygenase may be evolutionarily related. FEMS Microbiol Lett 132: 203-208.

Holmes ME, Sansone FJ, Rust TM, Popp BN. (2000). Methane production, consumption, and air-sea exchange in the open ocean: an evaluation based on carbon isotopic ratios. Global Biogeochem Cycles 14: $1-10$.

Horz HP, Rich V, Avrahami S, Bohannan BJM. (2005). Methane-oxidizing bacteria in a California upland grassland soil: diversity and response to simulated global change. Appl Environ Microbiol 71: 2642-2652.

Jensen S, Neufeld JD, Birkeland NK, Hovland M, Murrell JC. (2008). Insight into the microbial community structure of a Norwegian deep-water coral reef environment. Deep-Sea Res (I Oceanogr Res Pap) 55: 1554-1563.

Jones RD. (1991). Carbon-monoxide and methane distribution and consumption in the photic zone of the Sargasso Sea. Deep-Sea Res (Pt A Oceanogr Res Pap) 38: $625-635$.

Joye SB, Boetius A, Orcutt BN, Montoya JP, Schulz HN, Erickson $\mathrm{M}$ et al. (2004). The anaerobic oxidation of methane and sulfate reduction in sediments from Gulf of Mexico cold seeps. Chem Geol 205: 219-238.

Mau S, Valentine DL, Clark JF, Reed J, Camilli R, Washburn L. (2007). Dissolved methane distributions and air-sea flux in the plume of a massive seep field, Coal Oil Point, California. Geophys Res Lett 34: L22603.

Normark WR, Hein JR. (2003). Methane hydrate recovered from a mud volcano in Santa Monica Basin, offshore southern California. Eos Trans AGU 84(46), Fall Meet Suppl, Abstract OS51B-0855.

Norton JM, Alzerreca JJ, Suwa Y, Klotz MG. (2002). Diversity of ammonia monooxygenase operon in autotrophic ammonia-oxidizing bacteria. Arch Microbiol 177: 139-149.

Podgorsek L, Petri R, Imhoff JF. (2004). Cultured and genetic diversity, and activities of sulfur-oxidizing bacteria in low-temperature hydrothermal fluids of the North Fiji Basin. Mar Ecol-Prog Ser 266: 65-76.

Qiu QF, Noll M, Abraham WR, Lu YH, Conrad R. (2008). Applying stable isotope probing of phospholipid fatty acids and rRNA in a Chinese rice field to study activity and composition of the methanotrophic bacterial communities in situ. ISME J 2: 602-614.

Seifert R, Delling N, Richnow HH, Kempe S, Hefter J, Michaelis W. (1999). Ethylene and methane in the upper water column of the subtropical Atlantic. Biogeochemistry 44: 73-91.

Solomon EA, Kastner M, Jannasch H, Robertson G, Weinstein Y. (2008). Dynamic fluid flow and chemical fluxes associated with a seafloor gas hydrate deposit on the northern Gulf of Mexico slope. Earth Planet Sci Lett 270: 95-105.

Solomon EA, Kastner M, MacDonald IR, Leifer I. (2009). Considerable methane fluxes to the atmosphere from hydrocarbon seeps in the Gulf of Mexico. Nat Geosci 2: 561-565.

Steinberg DK, Carlson CA, Bates NR, Johnson RJ, Michaels AF, Knap AH. (2001). Overview of the US JGOFS Bermuda Atlantic time-series study (BATS): a decade-scale look at ocean biology and biogeochemistry. Deep-Sea Res (Pt Ii-Top Stud Oceanogr) 48: 1405-1447.

Tamura K, Dudley J, Nei M, Kumar S. (2007). MEGA4: molecular evolutionary genetics analysis (MEGA) software version 4.0. Mol Biol Evol 24: 1596-1599.

Tavormina PL, Ussler W, Orphan VJ. (2008). Planktonic and sediment-associated aerobic methanotrophs in two seep systems along the North American margin. Appl Environ Microbiol 74: 3985-3995.

Ussler W, Paull CK, Normark WR. (2006). Methane gas emanation from an active carbonate mound in Santa Monica Basin, offshore southern California. Geophys Res Abstr 8, Abstract 05223.

Valentine DL, Blanton DC, Reeburgh WS, Kastner M. (2001). Water column methane oxidation adjacent to an area of active hydrate dissociation, Eel River Basin. Geochim Cosmochim Acta 65: 2633-2640.

Ward BB, Kilpatrick KA, Novelli PC, Scranton MI. (1987). Methane oxidation and methane fluxes in the ocean surface-layer and deep anoxic waters. Nature 327: 226-229.

Wasmund K, Kurtboke DI, Burns KA, Bourne DG. (2009). Microbial diversity in sediments associated with a shallow methane seep in the tropical Timor Sea of Australia reveals a novel aerobic methanotroph diversity. FEMS Microbiol Ecol 68: 142-151.

Supplementary Information accompanies the paper on The ISME Journal website (http://www.nature.com/ismej) 